\title{
Examining Prospective Mathematics Teachers' Conceptual Structure Regarding the Concept of Integral
}

\author{
Alattin Ural (Corresponding author) \\ Faculty of Education, Department of Mathematics Education \\ Burdur Mehmet Akif Ersoy University, 15100, Burdur, Turkey \\ Tel: 90-248-2134024Ｅ-mail: ural@mehmetakif.edu.tr
}

Received: May 30, 2020 Accepted: June 23, 2020 Published: June 28, 2020

doi:10.5296/jei.v6i1.17115 URL: https://doi.org/10.5296/jei.v6i1.17115

\begin{abstract}
The purpose of this research is to identify prospective mathematics teachers' conceptual structure about the concept of "Integral". In this research, phenomenology design, one of the qualitative research designs, was used. A total of 35 prospective mathematics teachers, studying at a state university, participated in the research. The Word Association Test was conducted to collect the data. The data were analyzed according to content analysis and categories were given according to frequency values. Conceptual networks that present prospective mathematics teachers' cognitive structure about integral concept were drawn by using a "cut-off point" technique according to the frequency table. As a result, 14 categories related to integral concept were obtained.
\end{abstract}

Keywords: Integral, Conceptual structure, Word association test

\section{Introduction}

According to Tall and Vinner (1981), an individual's concept image for a given concept is "the total cognitive structure that is associated with the concept, which includes all the mental pictures and associated properties and processes" (Rösken \& Rolka, 2007). According to Sfard (1991), an individual is said to have a structural conception of a mathematical concept when he or she conceives the mathematical concept as if it is an abstract object in a static way whereas the individual is said to have an operational conception of the same concept when he or she focus the thinking on the processes, algorithms and actions contained in the concept (Habineza, 2013). The concept image of a mathematical concept is basically divided into two: Structural and Operational Understanding or Object-Process Perspective. The process understanding of a notation is the concept in which the concept is perceived as dynamic or detailed sequence of steps. An object (or structural) understanding is the concept where the 
concept is considered as a static structure and processes can be realized (Sfard, 1991). Process and object concepts complement each other and are therefore necessary for a deep understanding of mathematics. Sfard (1991) assumes that when concepts are developed, firstly operational or process understanding, and then structural or object understanding will come.

Integral is one of the important concepts of Calculus. The Fundamental Theorem of Calculus shows the relationship between integral and anti-derivative. The perspectives specified by Oberg (2000) on the concept of integral can be summarized as follows:

(1) Computation: Viewing the definite integral as a computation refers to evaluating it without reference to aspects such as area or summing processes. In most instances this involves applying The Fundamental Theorem of Calculus to a definite integral that contains an explicit function.

(2) Area: The area viewpoint refers to thinking about the definite integral in terms of area.

(3) Accumulation or Summation: Accumulation or summation refers to the notion of the definite integral as a summing process. Many students have difficulty conceptualizing the definite integral as a limit of a sum. In particular, it is not part of many students' understandings that the definite integral is connected with the procedure of dissecting an object, summing over all the pieces, and then making use of a limiting process.

(4) Total Change: Viewing the definite integral as a total change means understanding it as integrating a rate function over a closed interval $[a, b]$ to obtain a change in an amount function over the same interval. The change in an amount function corresponds to the change in an antiderivative of the rate function, and therefore can be found by using The Fundamental Theorem of Calculus. However, the notion of total change requires that The Fundamental Theorem of Calculus be seen as more than just a computational tool. The idea of total change is also the end result of taking the limit of a summing process in applied problems where the definite integral is the appropriate tool for the task.

(5) Function: When one views the definite integral as a function, one thinks of a function $G$ defined as,

$$
(x)=\int_{a}^{x} f(t) \mathrm{d} t
$$

where, a is some real number. Thus, the definite integral is viewed as an object in which the upper limit of integration is allowed to vary. Here one initially focuses on evaluating then integral function and describing the behavior of the graph of this function.

(6) Abstract Object: As an abstract object the definite integral is considered a formal object, independent of context. Thus, one analyzes the properties of the definite integral and its relationships to other mathematical objects. Included in this representation is knowing, and being able to work with, a definition for the definite integral.

In many textbooks, while indefinite integrals are typically presented as a family of functions with the related property of having all their derivatives equaling the integrand, definite 
integrals arise from areas under curves and are defined as the limit of Riemann sums (Jones $\&$ Thompson, 2017). The central conceptions of a definite integral are: procedure of anti-differentiation, area, and accumulation. Accumulation is an important but less widely understood interpretation. Accumulation is called "cumulative growth", "accumulation", "adding up pieces", "multiplicative-based summation", "rate-based accumulation" (Fisher, Samuels, \& Wangberg, 2016). Fisher, Samuels, and Wangberg (2016) stated those about these 3 concepts:

"Understanding in each of these 3 categories might be shallow or deep. For example, shallow understanding of antidifferentiation might include only procedural knowledge for basic functions (e.g., polynomial, trig, exponential). Deep understanding might include a full conception of the Fundamental Theorem of Calculus. A shallow understanding of area might include only the nominal notion itself. A deep understanding might allow reasoning about the bounds which maximize the integral given the graph of a function; it might encompass approximations through Riemann sums as well as exact answers from a definite integral. Shallow understanding of rate-based accumulation might only include a restatement of the Fundamental Theorem of Calculus. Deep knowledge might include the ability to set up integrals for applied problems or the ability to represent it with the graph of the antiderivative." (p. 1)

In the study conducted by Oberg (2000), it was stated that the undergraduate students regarded the definite integral most commonly as an area, closely followed by as a computation (the Fundamental Theorem of Calculus). Oberg stated that the accumulation or summation viewpoint and the function viewpoint were evoked almost equally after the abstract object viewpoint, and the total change viewpoint of the definite integral was the least used viewpoint. Also, he revealed that their perceptions of the integral concept were insufficient due to the lack of relationship with the concepts of function and integration.

The results of the research conducted by Serhan (2015) revealed that none of the students mentioned the Riemann sum in their image of the definite integral concept and that only a few of them mentioned the antiderivative in their images. In the study conducted by Akrouti (2019); it was determined that students associated the concept of integral with the concepts of anti-derivative, area and integration (Riemann sum). It was pointed out that few students considered the integral as an integration process. In their research, Rasslan and Tall (2002) expressed that most of the high school students had an "a procedure of calculation" comprehension of the concept of the definite integral and the rest of them perceived it as the area between the function and $\mathrm{x}$-axis in $[\mathrm{a}, \mathrm{b}]$.

The research by Jones and Thompson (2017) revealed that the most students described definite and indefinite integrals as representing the area under a curve, or both as representing an anti-derivative. In other words, it appears that many students' concept images for "integral" may have merged both types of integrals into essentially the same mathematical object-as a geometric area, or as an algebraic function, or both. Moru and Qhobela (2019) stated that the word anti-derivative was also used synonymously with integration, integral, inverse and back to original function by the students. In the study carried out with graduate students by Delice and Sevimli (2011); the findings indicated that the experimental group 
students (first definite integral then indefinite integral) predominantly had the "area" image and the control group (indefinite integral-definite integral) had the "inverse of derivative" image.

Kouropatov (2016) stated that high school students, even those who learn mathematics at the high level, who learned the concept of the integral according to the common approach don't have an "accumulational" comprehension of the concept of the integral with respect to the definition of comprehension. He said that the students understood the concept in a formal-procedural, non-consistent way that includes notions of antiderivative and area. The results from the research by Fisher, Samuels, and Wangberg (2016) showed that the majority of students described the definite integral in terms of area and roughly half of the remaining students described it in terms of an antiderivative.

In the current study, it was tried to obtain knowledge about the mathematics teacher candidates' concept images related to the concept of integral through word association test. In this study, unlike other studies, the concept images of the prospective mathematics teacher candidates are presented as a whole without being separated as definite or indefinite integral. In addition, unlike other studies, concept images of students were not obtained through integral problems, but were obtained through general connotations of the concept in students. This study responds to a need for research into the understanding of the integral, and it could influence methodology for the teaching of the integral. With more research results to understand the students' understanding of the integral, a good scheme of the concept of integral can be drawn up, so this schema can be used to improve classroom instruction.

\section{Method}

\subsection{Research Model}

The design of the research is phenomenology, one of the qualitative research designs. As it is known, there is no concern about generalization in qualitative research. However, a study is carried out to better explain a case. In this study, conceptual structures of prospective mathematics teachers related to the concept of "Integral" were examined.

\subsection{Data Collection Tool}

Discrete word association test was used as data collection tool. This is a reliable technique used as a procedure for measuring number, direction and strengths of connections (Novak \& Govin, 1984; Mervis \& Rosh, 1981). Free word association test requires responses that are not restricted to any specific category or class of words. In tests of discrete word association, each participant is asked to produce only a single associate to each word, while in tests of continuous association, the stimulus word or the list of stimulus words is presented to the respondents only once and they are asked to give as many associations as they can in a pre-specified period of time (Kostova \& Radoynovska, 2008). The data collection tool that was used in the current research, was given below:

"Write 10 concepts that evoke the concept of "Integral" (Duration is 60 seconds)

Integral: 
Integral:

Integral:

Integral:

Integral:

Integral:

Integral:

Integral:

Integral:

Integral:

\subsection{Validity and Reliability}

Data analysis was carried out by 2 mathematics educators. Firstly, the categories by grouping the similar words that the participants produced, formed by independently. Then, the categories were compared. Since the answers are very clear mathematical terms such as "area", "volume", "inverse of derivative", "border", it is observed that there is a great deal of agreement $(90 \%)$. The remaining parts are coded by consensus.

\subsection{Analysis of Data}

A detailed frequency table was prepared to show how many times, and which words and concepts were repeated in response to a key concept. Using the frequency table, a concept map was created. The breakpoint technique suggested by Bahar, Johnstone, and Sutcliffe (1999) was used in the creation of the concept map. In the breakpoint technique, a certain value below the most frequently given response word was determined as the breakpoint for each key concept in the frequency table. The concepts above this value constitute the first part of the concept map. Afterwards, the breakpoint is periodically lowered and the process is continued until all the key words appear on the concept map. Using this technique in the data analysis, ten concept maps were created according to the following breakpoints: 1-10, 11-20, 21-30 and 31-40.

\section{Results}

The categories and words obtained regarding the concept of integral are given in Table 1 as frequency table. The categories here were created by bringing together the similar words which the participants gave about the integral concept. In other words, it is the mathematical concept in the focus of similar words. 
Table 1 . The frequency table regarding category and words

\begin{tabular}{|c|c|c|c|c|}
\hline Category & Words & Frequency & Total & Breakpoint \\
\hline \multirow[t]{4}{*}{ Derivative } & Derivative & 12 & \multirow[t]{4}{*}{38} & \multirow[t]{4}{*}{$31-40$} \\
\hline & Invers of derivative & 15 & & \\
\hline & Primitive Function & 2 & & \\
\hline & Anti-derivative & 9 & & \\
\hline Volume & Volume & 28 & 28 & $21-30$ \\
\hline Area & Area & 27 & 27 & $21-30$ \\
\hline \multirow[t]{3}{*}{ Differential } & Differential & 17 & \multirow[t]{3}{*}{27} & \multirow[t]{3}{*}{$21-30$} \\
\hline & $\mathrm{dx}$ & 3 & & \\
\hline & Variation & 7 & & \\
\hline \multirow[t]{3}{*}{ Calculus } & Calculus & 10 & \multirow[t]{3}{*}{15} & \multirow[t]{3}{*}{$11-20$} \\
\hline & Theorem-Proof & 3 & & \\
\hline & Mathematics & 2 & & \\
\hline Function & Function & 14 & 14 & $11-20$ \\
\hline \multirow[t]{2}{*}{ Curve } & Graphics & 7 & \multirow[t]{2}{*}{13} & \multirow[t]{2}{*}{$11-20$} \\
\hline & Curve & 6 & & \\
\hline \multirow[t]{3}{*}{ Convergence test } & Convergence & 2 & \multirow[t]{3}{*}{10} & \multirow[t]{3}{*}{$1-10$} \\
\hline & Limit & 7 & & \\
\hline & Sequence & 1 & & \\
\hline \multirow[t]{3}{*}{ Solids } & Solids & 7 & \multirow[t]{3}{*}{9} & \multirow[t]{3}{*}{$1-10$} \\
\hline & 3-dimensional & 1 & & \\
\hline & Space & 1 & & \\
\hline \multirow[t]{2}{*}{ Exam } & Exam & 7 & \multirow[t]{2}{*}{9} & \multirow[t]{2}{*}{$1-10$} \\
\hline & Difficult question & 2 & & \\
\hline Boundary & Boundary & 8 & 8 & $1-10$ \\
\hline \multirow[t]{3}{*}{ Integration } & Summation & 2 & \multirow[t]{3}{*}{4} & \multirow[t]{3}{*}{$1-10$} \\
\hline & Accumulation & 1 & & \\
\hline & All of the parts & 1 & & \\
\hline Arc length & Arc length & 3 & 3 & $1-10$ \\
\hline Equation & Equation & 3 & 3 & $1-10$ \\
\hline 14 & 30 & & 208 & \\
\hline
\end{tabular}

As a result, 14 categories and 30 words related to the concept of "Integral" were obtained. From Table 1, it is seen that the mathematics teacher candidates associated the concepts of 


\section{Macrothink}

derivative $(18 \%)$, volume $(14 \%)$, area $(13 \%)$, differential $(13 \%)$, function $(7 \%)$, curve $(6 \%)$, convergence test (5\%), solids (4\%), boundary (4\%), arc length $(1 \%)$ and equation $(1 \%)$ in terms of mathematical concepts. In this case, the concept of integral was associated with mathematical concepts at the rate of $86 \%$. In terms of concepts that are not related to mathematical terminology in the first degree, it is observed that they establish a relationship with the concepts of calculus course (7\%), exam (4\%) and integration $(2 \%)$ respectively. In this case, $13 \%$ has been associated with non-mathematical concepts. The concept of "integration" here can be seen as the mental image of the process of taking into account the sum of the rectangular regions created in the process of finding the area under a curve while introducing students to the concept of integral.

When the rates belonging to the categories are taken into consideration; these 14 concepts associated with the concept of integral can be divided into ordered groups (can be leveled) as stated in Table 2.

Table 2. Category Levels

\begin{tabular}{|l|l|l|}
\hline Level & Category & Rate \\
\hline 1 & Derivative & $\% 18$ \\
\hline \multirow{4}{*}{3} & Volume & $\% 14$ \\
\cline { 2 - 3 } & Area & $\% 13$ \\
\cline { 2 - 3 } & Differential & $\% 13$ \\
\hline \multirow{5}{*}{4} & Calculus & $\% 7$ \\
\cline { 2 - 3 } & Function & $\% 7$ \\
\cline { 2 - 3 } & Curve & $\% 7$ \\
\hline \multirow{5}{*}{} & Convergence test & $\% 5$ \\
\cline { 2 - 3 } & Solids & $\% 4$ \\
\cline { 2 - 3 } & Exam & $\% 4$ \\
\cline { 2 - 3 } & Boundary & $\% 4$ \\
\cline { 2 - 3 } & Integration & $\% 1$ \\
\cline { 2 - 3 } & Arc length & $\% 1$ \\
\cline { 2 - 3 } & Equation & \\
\hline
\end{tabular}

The information given in Table 2 was visually represented by the pie chart in Figure 1 based on the rates. The size of the slices here is given in proportion to the proportion of the relevant category. 


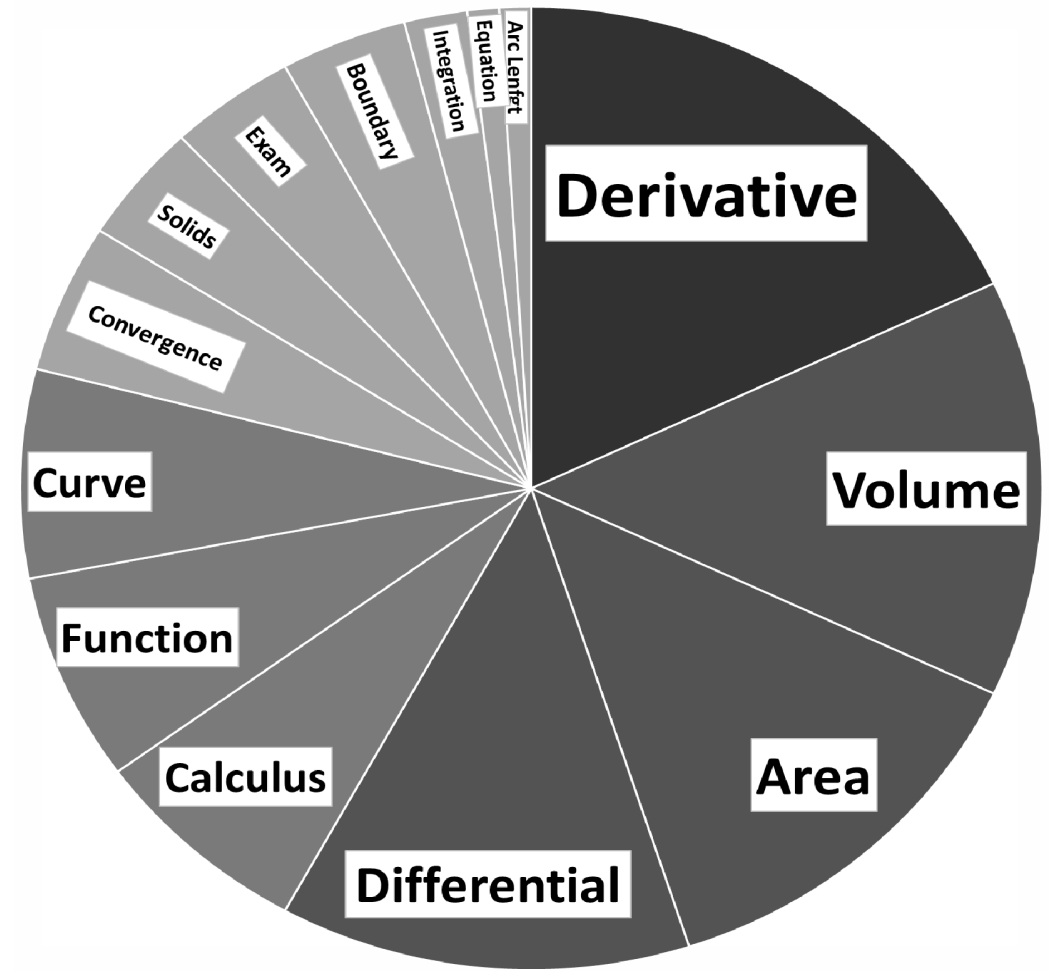

Figure 1. Conceptual structure related to the concept of integral

\section{Discussion and Conclusion}

As a result of the research; it is observed that the mathematics teacher candidates associated the concept of integral with the concept of derivative (level 1), volume, area, differential (level 2); function, curve (level 3); convergence test, solids, boundary, integration, arc length, equation (level 4). The fact that the first three concepts that the concept of integral is associated with are derivative, area and volume can be thought as the mathematics teacher candidates commonly have an operational (procedural) conception. In a study by Nurwahyu \& Tinungki (2020); it was stated that most of the undergraduate students had procedural skills regarding the concept of integral. It is also stated that this situation showed their beliefs of solving the problem easily and in a short time.

In the study conducted by Oberg (2000), it was stated that the undergraduate students regarded the definite integral most commonly as an area, closely followed by as a computation (the Fundamental Theorem of Calculus). Oberg stated that the accumulation or summation viewpoint and the function viewpoint were evoked almost equally after the abstract object viewpoint, and the total change viewpoint of the definite integral was the least used viewpoint. Also, he revealed that their perceptions of the integral concept were insufficient due to the lack of relationship with the concepts of function and integration.

The results of the research conducted by Serhan (2015) indicated that the students' most dominant knowledge was the procedural and that they had limited understanding of the definite integral; their abilities to represent the concept in different ways were limited; they 
could represent the concept using only two different representations. In addition to that, the results of this study revealed that none of the students mentioned the Riemann sum in their image of the definite integral concept and that only a few of them mentioned the antiderivative in their images.

In the study conducted by Akrouti (2019); it was determined that students associated the concept of integral with the concepts of anti-derivative, area and integration (Riemann sum). However, in this study, it was stated that the students' integral concept information contradicted with the formal definition and was therefore structurally inadequate. It was pointed out that few students considered the integral as an integration process, so they could treat the integral not only as a process but also as an object.

In the study carried out with graduate students by Delice and Sevimli (2011); the findings indicated that the experimental group students (first definite integral then indefinite integral) predominantly had the "area" image and the control group (indefinite integral-definite integral) had the "inverse of derivative" image. Students in both groups mainly used these concept images when defining the concept and had difficulties in providing the formal definition. In generalized integral problems, the students who had the image of integral as the inverse of derivative were observed to obtain wrong solutions using The Fundamental Theorems of Calculus without considering the points where the function is discontinuous. On the other hand, the students who had the image of integral as the area below the curve obtained correct answers more easily in the same type of problems by analyzing the integral in two parts where the function is discontinuous. The researchers emphasized that an introduction to the concept of integral with the indefinite integral could limit images of the concept of definite integral.

\section{References}

Akrouti, I. (2019). Students' conceptions of the definite integral in the first year of studying science at university. Paper presented at the Eleventh Congress of the European Society for Research in Mathematics Education, Utrecht University, Utrecht, Netherlands.

Bahar, M., Johnstone, A. H., \& Sutcliffe, R. G. (1999). Investigation of students' cognitive structure in elementary genetics through word association tests. Journal of Biological Education, 33, 134-141. https://doi.org/10.1080/00219266.1999.9655653

Delice, A., \& Sevimli, E. (2011). Investigation of concept images in the topical order of teaching integrals; Definite and indefinite integrals. Pamukkale University Journal of Education, 30 .

Fisher, B., Samuels, J., \& Wangberg, A. (2016). Student conceptions of definite integration and accumulation functions. In E. Johnson, S. Larsen, \& F. Rutherford (Eds.), Proceedings of the 19th Annual Conference on Research in Undergraduate Mathematics Education (CRUME) (pp. 761-767). Pittsburgh, PA: The Special Interest Group of the Mathematical Association of America on Research in Undergraduate Mathematics Education (SIGMAA-RUME).

Habineza, F. (2013). A case study of analyzing student teachers' concept images of the 
definite integral. Rwandan Journal of Education, 1(2).

Kostova, Z., \& Radoynovska, B. (2008). Word association test for studying conceptual structures of teachers and students. Bulgarian Journal of Science and Education Policy, 2(2), 209-231.

Kouropatov, A. (2016). The Integral Concept in High School: Constructing Knowledge about Accumulation (Unpublished Doctoral Theses, Tel Aviv University, Tel Aviv, Israel).

Mervis, C. B., \& Rosh, E. (1981). Categorization of natural objects. Annual Review of Psychology, 32, 89-115. https://doi.org/10.1146/annurev.ps.32.020181.000513

Moru, E. K., \& Qhobela, M. (2019). Social science students' concept images and concept definitions of anti-derivatives. Pythagoras, 40(1), 484. https://doi.org/10.4102/pythagoras. v40i1.484

Novak, J. D., \& Govin, D. B. (1984). Learning how to learn. New York: Cambridge University Press. https://doi.org/10.1017/CBO9781139173469

Nurwahyu, B., \& Tinungki, G. M. (2020). Concept image and its influence on beliefs: Case study on undergraduate engineering students in solving of calculus concept problems. International Journal of Advanced Science and Technology, 29(5).

Oberg, T. D. (2000). An investigation of undergraduate calculus students' conceptual understanding of the definite integral (Unpublished Doctoral Theses, The University of Montana, Missoula, USA).

Rasslan, S., \& Tall, D. (2002, July). Definitions and images for the definite integral concept. Paper presented at the 26th Conference of the International Group for the Psychology of Mathematics Education, Norwich, United Kingdom.

Rösken, B., \& Rolka, K. (2007). Integrating intuition: the role of concept image and concept definition for students' learning of integral calculus. Montana Council of Teachers of Mathematics (TMME Monograph), 3, 181-204.

Serhan, D. (2015). Students' understanding of the definite integral concept. International Journal of Research in Education and Science, 1(1), 84-88. https://doi.org/10.21890/ijres. 00515

Sfard, A. (1991). On the dual nature of mathematical conceptions: Reflections on processes and objects as different sides of the same coin. Educational Studies in Mathematics, 22, 1-36. https://doi.org/10.1007/BF00302715

Steven, R. J., \& Thompson, C. S. R. (2017). Definite integrals versus indefinite integrals: How do students see them as the same or as different? Paper presented at the Conference on Research in Undergraduate Mathematics Education, San Diego, CA.

Tall, D., \& Vinner, S. (1981). Concept Image and concept definition in mathematics with reference to limits and continuity. Educational Studies in Mathematics, 12, 151-169. https://doi.org/10.1007/BF00305619 


\section{Copyright Disclaimer}

Copyright for this article is retained by the author(s), with first publication rights granted to the journal.

This is an open-access article distributed under the terms and conditions of the Creative Commons Attribution license (http://creativecommons.org/licenses/by/3.0/). 